\title{
Penentuan Rute Distribusi Suku Cadang Kendaraan Bermotor dalam Meminimalkan Biaya Transportasi (Studi Kasus: PT. Inti Polymetal Karawang)
}

\section{Determining Route of Spare Part of Motor Vehicles in Minimizing Transportation Costs (Case Study: PT. Inti Polymetal Karawang)}

\author{
Ade Momon S. ${ }^{1 *}$, Damara Widi Ardiatma ${ }^{2}$ \\ ${ }^{1,2}$ Program Studi Teknik Industri, Universitas Singaperbangsa Karawang, Jl. H. S. Ronggowaluyo, \\ Telukjambe Timur, Karawang 41361, Indonesia
}

Diterima: 29 Januari 2018; Direvisi: 15 Februari 2018; Disetujui: 23 Februari 2018

\begin{abstract}
ABSTRAK
Tujuan dari sistem distribusi adalah mengantarkan produk dengan cepat, cepat dan menghasilkan biaya minimum. Oleh karena itu, pengembangan sistem distribusi sangat penting karena dapat menunjang pertumbuhan dan perkembangan perusahaan. Penelitian ini bertujuan untuk mendapatkan jalur penyampaian produk yang paling tepat dan optimal serta mendapatkan penghematan biaya transportasi. PT. IPM adalah perusahaan yang bergerak di bidang produksi otomotif. Permasalahan yang dihadapi PT. IPM adalah tidak adanya perencanaan distribusi produk yang baik dan proses distribusi penjadwalan dianggap tidak maksimal. Hal ini disebabkan banyaknya rute yang terlalu banyak, jarak pengirimannya terlalu jauh, keterbatasan sarana pengangkutan dan pemanfaatan ruang transportasi kurang maksimal dan tingginya biaya transportasi. Untuk mengatasi masalah PT. IPM, maka diperlukan metode terbaik, yaitu metode Saving Matrix yang digunakan untuk menentukan rute distribusi produk ke pelanggan berdasarkan kapasitas alat angkut yang digunakan dan metode Tetangga Terdekat untuk pemesanan rute. Dari hasil perhitungan matematis dengan metode Saving Matrix dan algoritma dengan metode Tetangga Terdekat diperoleh 49 rute terbaik untuk PT. IPM. Jarak yang ditempuh sejauh 6.010 kilometer dengan biaya transportasi Rp. 46.630.527. Penghematan jarak yang dihasilkan adalah 22\% (1.690,9 km), sedangkan penghematan biaya transportasi yang terjadi adalah 38\% atau Rp. 28.494.021.
\end{abstract}

Kata Kunci: Rute, Saving Matrix, Nearest Neighbor, Transportasi

\begin{abstract}
The goal of the distribution system is to deliver the product promptly, quickly and generate the minimum cost. Therefore, the development of distribution system is very important because it can support the growth and development of the company. This study aims to get the route of delivery of the most appropriate and optimal products and get transportation cost savings. PT. IPM is a company engaged in the production of automotive. The problems faced by PT. IPM is the absence of good product distribution planning and scheduling distribution process is considered not maximal. This is due to the number of routes are too many, the distance is too far delivery, the limited means of conveyance and utilization of transport space less than the maximum and the high cost of transportation. To solve the problem of PT. IPM then needed the best method, that is Saving Matrix method which is used to determine product distribution route to the customer based on the capacity of conveyance used and Nearest Neighbors method for route ordering. From the result of mathematical calculation with Saving Matrix method and algorithm with Nearest Neighbors method obtained 49 best routes for PT. IPM. The distance to be taken is as far as 6,010 kilometers with transportation cost of $R p .46,630,527$. The resulting distance saving is $22 \%(1,690.9 \mathrm{~km})$, while the transportation cost savings that occur is $38 \%$ or Rp. 28,494,021.
\end{abstract}

Keywords: Route, Saving Matrix, Nearest Neighbor, Transportation.

*e-mail: ade.momon@staff.unsika.ac.id 


\section{PENDAHULUAN}

\subsection{Latar Belakang}

Transportasi dan distribusi merupakan

dua komponen yang mempengaruhi keunggulan kompetitif suatu perusahaan karena penurunan biaya transportasi dapat meningkatkan keuntungan perusahaan secara tidak langsung. Salah satu cara untuk menurunkan biaya transportasi adalah dengan mengefisienkan sistem distribusi dan penggunaan jenis transportasi yang ada (Pujawan, 2005).

PT. Inti Polymetal adalah salah satu perusahaan manufaktur yang bergerak dalam bidang produksi suku cadang kendaraan bermotor. Dalam aktivitas pendistribusian tersebut PT. Inti Polymetal mendistribusikan produk-produknya ke pelanggan yang ada di kota Jakarta, Bekasi, Cikarang, Purwakarta dan Karawang yang tercatat ada 16 pelanggan. Sasaran sistem distribusi PT. Inti Polymetal adalah melakukan pengiriman produk secara tepat, cepat dan menghasilkan biaya yang minimum.

Permasalahan yang sedang dihadapi oleh PT. Inti Polymetal selama ini menurut Bapak Badrudin selaku kepala bagian di bagian distribusi adalah belum adanya perencanaan distribusi produk yang baik dan penjadwalan proses distribusi dinilai belum maksimal. Hal ini disebabkan oleh jumlah rute terlalu banyak, jarak pengiriman terlalu jauh, terbatasnya alat angkut dan utilisasi ruang alat angkut yang kurang maksimal serta tingginya biaya transportasi. Selama ini perusahaan sedang mencari solusi untuk mengembangkan sistem pendistribusian yang efektif dan efisien dalam melakukan proes pendistribusian barang dengan mempertimbangkan jarak antar pelanggan dan kapasitas alat angkut yang digunakan sehingga tidak menimbulkan banyak rute yang berbeda dan jauhnya jarak yang ditempuh dalam pengiriman sehingga dapat meminimumkan biaya transportasi. Dalam pendistribusian barang juga terjadi inkonsistensi jadwal pendistribusian di setiap harinya dikarenakan belum adanya standar rute distribusi yang jelas dan inkonsistensi jadwal pendistribusian di setiap harinya ini menyebabkan ketergantungan yang sangat tinggi kepada daya ingat dan ketelitian operator bagian perencanaan distribusi. Salah satu metode yang digunakan untuk memecahkan permasalahan rute pengiriman, yaitu metode saving matrix, serta metode tersebut dianggap sebagai prosedur terbaik diantara the nearest neighbour, farthest insert dan insert nearest (Sarjono, 2014).

Penelitian sebelumnya melakukan evaluasi manajemen transportasi untuk menentukan jalur distribusi pada rantai supply dengan kombinasi perhitungan matriks jarak dan jumlah permintaan kertas tiap konsumen diperoleh matriks penghematan atau Saving Matriks pada jumlat alat transportasi yang diperlukan, rute jalur distribusi bahkan hingga biaya transportasi (Hutabarat, 2008).

Dalam menentukan rute optimal distribusi produk dalam menggunakan metode saving matriks diperlukan beberapa variabel yang digunakan seperti halnya rute awal distribusi, lokasi customer, kapasitas alat angkut, biaya distribusi, dan permintaan, dengan variabel terikatnya meminimunkan biaya distribusi. Sehingga, langkah-langkah yang harus ditempuh dengan mengindentifikasikan matriks jarak, mengindentifikasikan matriks penghematan atau saving matrix, mengalokasikan retailer kendaraan atau rute, hingga mengurutkan retailer kedalam rute yang sudah terdefinisi (Effendi, Ngatilah dan Iriani, 2016).

Menggunakan metode saving matrix dan nearest neighbour menghasilkan sub rute yang lebih sedikit dari rute distribusi yang diterapkan perusahaan, sehingga menghasilkan usulan model dalam menentukan rute distribusi untuk meminimalkan biaya transportasi dengan (Rahmawati, Nazaruddin dan Sari, 2014).

Penggunaan metode saving matrix dan nearest neighbour dalam penelitian bertujuan untuk mendapatkan rute pengiriman produk yang paling tepat dan optimal untuk meminimalkan biaya transportasi serta mendapatkan penghematan biaya transportasi.

\section{METODOLOGI}

Data yang diperlukan dalam penelitian ini yaitu data peta perjalanan, jenis dan jumlah angkutan yang digunakan, data 
kapasitas alat angkut dan kapasitas terima, kapasitas waktu tersedia, data permintaan, matrik jarak, data biaya ntuk kendaraan dan data gaji driver dalam menyelesaikan permasalahan di penelitian ini. Selanjutnya dilakukan penjadwalan kendaraan menggunakan Saving Matrix dan menentukan urutan pelanggan yang harus dikunjungi menggunakan algoritma Nearest Neighbour. Flow chart metode penelitian dapat dilihat pada Gambar 1.

\section{a. Metode Saving Matrix}

Metode untuk meminimumkan jarak atau waktu atau ongkos dengan mempertimbangkan kendala-kendala yang ada. Digunakan jarak sebagai fungsi tujuan apabila diketahui koordinat tujuan pengiriman, lalu jarak yang akan ditempuh oleh semua kendaraan akan diminimumkan. Langkah-langkah yang harus dikerjakan, yaitu mengidentifikasi matrix jarak, mengidentifikasi matrix penghematan (saving matrix), mengalokasikan tujuan dalam rute perjalanan kendaraan, mengurutkan tujuan dalam rute yang terdefinisi.

\section{b. Metode Nearest Neighbour}

Prosedur ini memulai rute kendaraannya dari jarak yang paling dekat dengan depot/gudang perusahaan. Kemudian rute selanjutnya yang paling terdekat dengan tujuan.

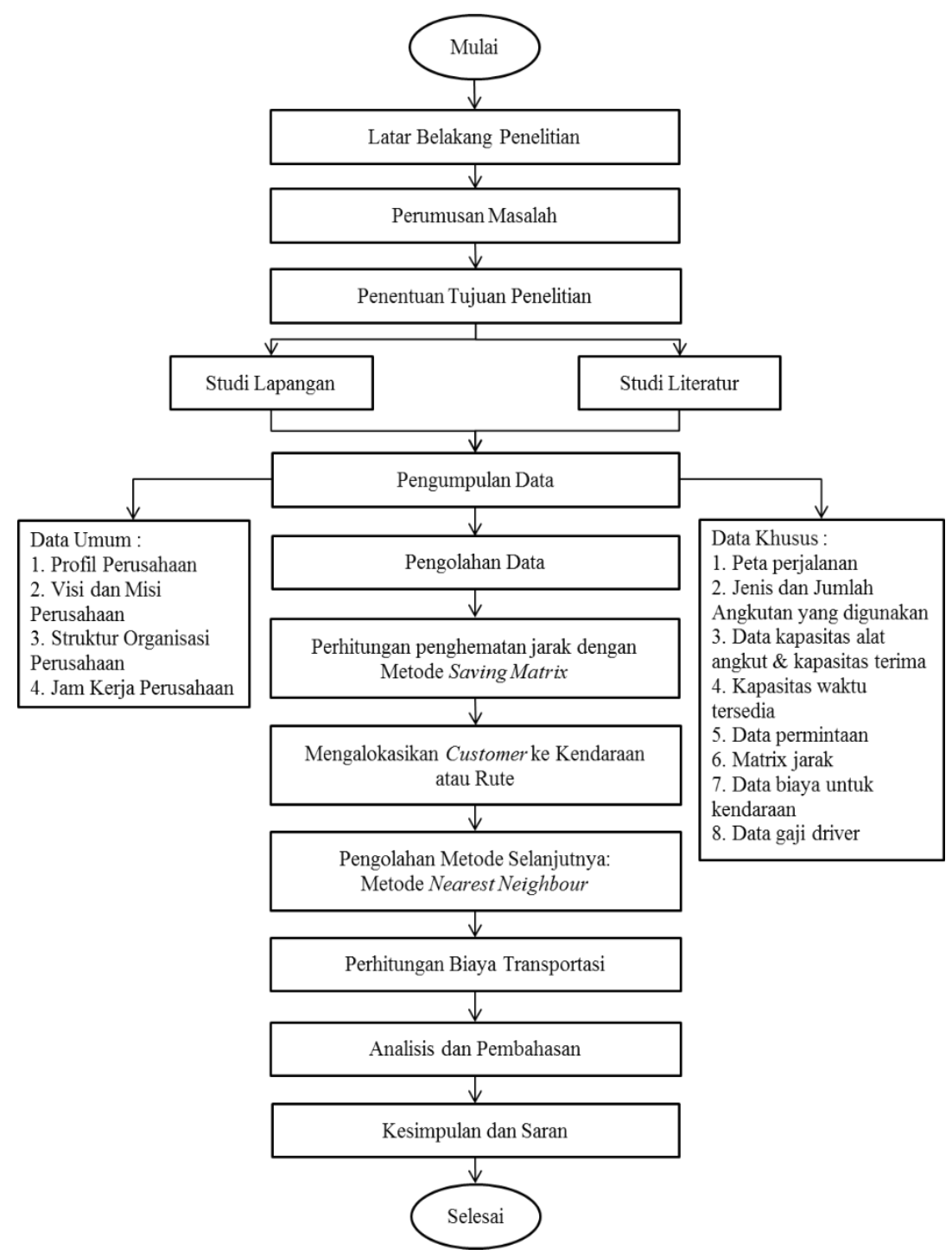

Gambar 1. Flow Chart Penelitian 


\section{HASIL DAN PEMBAHASAN}

PT. Inti Polymetal saat ini mempunyai 16 pelanggan yang tersebar di Kota-kota kawasan industri yang akan dilalui saat distribusi yaitu Jakarta, Bekasi, Cikarang, Purwakarta dan Karawang. Untuk lebih mempermudah perhitungan, maka setiap pelanggan diberikan nama khusus/kode $(C i)$. Data lokasi tujuan dapat dilihat pada Tabel 1.

\subsection{Pengumpulan Data}

Pada penelitian ini, pengumpulan data dengan memasukan data variabel berupa data permintaan, jumlah dan kapasitas kendaraan, serta jarak pendistribusian. Data yang dikumpulkan kemudian diolah dalam pembuatan saving matriks.

\section{a. Data Permintaan}

Dalam melakukan penelitian ini diperlukan data mengenai produk yang akan dikirim ke pelanggan, oleh karena itu yang digunakan sebagai bahasan penelitian ini yaitu data permintaan semua pelanggan bulan Maret 2017. Adapun yang dipaparkan yaitu berdasarkan aktual pengiriman per hari berdasarkan permintaan dari pelanggan, sehingga jumlah muatan kendaraan selalu berbeda-beda berdasarakan permintaan tersebut.

\section{b. Jumlah dan Kapasitas Kendaraan}

Pada lokasi, tersedia 5 unit kendaraan yang akan melaksanakan pendistribusian produk berdasarkan rute yang telah ditentukan, kendaraan tersebut yaitu Truk Fuso Syncrum yang digunakan untuk semua pelanggan dengan kapasitas muatan sebesar 18.000 pcs.

\section{c. Jarak Pendistribusian}

Jarak pendistribusian merupakan jarak tempuh yang harus dilalui kendaraan dari PT. IPM (0) ke pelanggan atau jarak antar pelanggan. Pengukuran jarak ini diperoleh menggunakan program aplikasi Google Maps. Adapun hasil matrik jarak untuk permintaan tanggal 06 Maret 2017 dapat dilihat pada Tabel 2 .

Tabel 1. Lokasi tujuan distribusi

\begin{tabular}{lc}
\hline \multicolumn{1}{c}{ Pelanggan } & Kode \\
\hline PT. SIM 4W Tambun & C1 \\
PT. SIM 4W GIIC & C2 \\
PT. AHM Plant 1 & C3 \\
PT. AHM Plant 2 & C4 \\
PT. AHM Plant 3\&3A & C5 \\
PT. AHM Plant 4\&5 & C6 \\
PT. KICI & C7 \\
PT. NISSAN & C8 \\
PT. AJC & C 9 \\
PT. KFN & C10 \\
PT. FTI & C11 \\
PT. FSI & C12 \\
PT. NAMICOH & C13 \\
PT. PPA & C14 \\
PT. GANSA & C15 \\
PT. KBU Tambun & C16 \\
\hline
\end{tabular}

3.2. Pengolahan Data dalam Pembuatan Matriks Penghematan (Saving Matrix)

Matriks penghematan ini dibuat berdasarkan matriks jarak dengan menggunakan rumus seperti ditunjukkan pada persamaan (1). Matriks penghematan terhadap jarak untuk tanggal 06 Maret 2017 ini dapat dilihat pada Tabel 3.

$$
S(y, x)=J(G, x)+J(G, y)-J(x, y)
$$




\begin{tabular}{|c|c|c|c|c|c|c|c|c|c|c|c|c|c|c|c|}
\hline \multicolumn{6}{|c|}{$\begin{array}{l}\text { Versi online: } \\
\text { http://journal.ubm.ac.id/index.php/jiems } \\
\text { DOI: dx.doi.org/10.30813/jiems.v11i1.1012 } \\
\text { Hasil Penelitian } \\
\end{array}$} & \multicolumn{10}{|c|}{$\begin{array}{r}\text { Journal of Industrial Engineering and Management Systems } \\
\text { Vol. 11, No. 1, 17-24, } 2018 \\
\text { ISSN 1979-1720 } \\
\text { E-ISSN 2579-8154 } \\
\end{array}$} \\
\hline Dari / ke & 0 & $\mathrm{C} 1$ & $\mathrm{C} 2$ & $\mathrm{C} 3$ & $\mathrm{C} 4$ & $\mathrm{C} 5$ & $\mathrm{C} 6$ & $\mathrm{C} 7$ & $\mathrm{C} 8$ & C9 & $\mathrm{C} 10$ & $\mathrm{C} 11$ & $\mathrm{C} 13$ & $\mathrm{C} 14$ & $\mathrm{C} 15$ \\
\hline 0 & 0.00 & & & & & & & & & & & & & & \\
\hline $\mathrm{C} 1$ & 36.30 & 0.00 & & & & & & & & & & & & & \\
\hline $\mathrm{C} 2$ & 20.00 & 30.20 & 0.00 & & & & & & & & & & & & \\
\hline $\mathrm{C} 3$ & 61.30 & 30.10 & 52.60 & 0.00 & & & & & & & & & & & \\
\hline $\mathrm{C} 4$ & 56.40 & 27.20 & 47.70 & 7.80 & 0.00 & & & & & & & & & & \\
\hline $\mathrm{C} 5$ & 31.00 & 15.90 & 22.20 & 38.80 & 34.20 & 0.00 & & & & & & & & & \\
\hline C6 & 30.60 & 58.50 & 40.30 & 81.40 & 76.70 & 51.30 & 0.00 & & & & & & & & \\
\hline $\mathrm{C} 7$ & 33.10 & 61.00 & 42.80 & 83.90 & 79.20 & 53.80 & 4.60 & 0.00 & & & & & & & \\
\hline $\mathrm{C} 8$ & 32.60 & 60.50 & 42.30 & 83.40 & 78.80 & 53.30 & 4.40 & 1.70 & 0.00 & & & & & & \\
\hline C9 & 33.60 & 61.50 & 43.30 & 84.30 & 78.10 & 54.30 & 5.00 & 1.80 & 1.20 & 0.00 & & & & & \\
\hline $\mathrm{C} 10$ & 45.10 & 16.10 & 36.40 & 33.50 & 29.00 & 19.10 & 63.70 & 67.60 & 66.60 & 67.60 & 0.00 & & & & \\
\hline $\mathrm{C} 11$ & 3.20 & 36.80 & 18.60 & 59.60 & 53.50 & 29.60 & 27.10 & 31.00 & 30.60 & 31.50 & 42.90 & 0.00 & & & \\
\hline $\mathrm{C} 13$ & 28.00 & 25.20 & 15.50 & 48.00 & 41.80 & 18.00 & 46.10 & 50.00 & 49.50 & 50.50 & 21.50 & 26.40 & 0.00 & & \\
\hline $\mathrm{C} 14$ & 27.30 & 24.50 & 14.70 & 47.30 & 41.20 & 17.30 & 45.40 & 49.30 & 48.80 & 49.80 & 20.70 & 25.70 & 2.90 & 0.00 & \\
\hline $\mathrm{C} 15$ & 27.10 & 24.30 & 14.60 & 47.10 & 40.90 & 17.00 & 45.20 & 49.00 & 48.60 & 49.50 & 23.00 & 25.50 & 2.10 & 4.10 & 0.00 \\
\hline
\end{tabular}

Tabel 3. Matriks Penghematan Jarak dengan Menggabungkan Dua Rute yang Berbeda

\begin{tabular}{ccccccccccccccc}
\hline Dari/ke & C1 & C2 & C3 & C4 & C5 & C6 & C7 & C8 & C9 & C10 & C11 & C13 & C14 & C15 \\
\hline C1 & 0.00 & & & & & & & & & & & & & \\
C2 & 26.10 & 0.00 & & & & & & & & & & & \\
C3 & $\mathbf{6 7 . 5 0}$ & 7.70 & 0.00 & & & & & & & & & & \\
C4 & $\mathbf{6 5 . 5 0}$ & 9.70 & $\mathbf{9 2 . 5 0}$ & 0.00 & & & & & & & & & \\
C5 & 51.40 & 23.90 & 36.00 & 12.40 & 0.00 & & & & & & & & & \\
C6 & 8.40 & 48.40 & 11.50 & 12.50 & $\mathbf{5 9 . 6 0}$ & 0.00 & & & & & & & & \\
C7 & 8.40 & 48.40 & 11.50 & 12.50 & $\mathbf{5 9 . 6 0}$ & $\mathbf{1 0 0 . 5 0}$ & 0.00 & & & & & & & \\
C8 & 8.40 & 48.40 & 11.50 & 12.40 & $\mathbf{5 9 . 7 0}$ & $\mathbf{1 0 0 . 2 0}$ & 7.30 & 0.00 & & & & & & \\
C9 & 8.40 & 48.40 & 11.60 & 14.00 & $\mathbf{5 8 . 0 0}$ & $\mathbf{1 0 0 . 6 0}$ & 7.80 & 2.30 & 0.00 & & & & & \\
C10 & $\mathbf{6 5 . 3 0}$ & 9.90 & 55.50 & 12.30 & 44.10 & 6.70 & 0.70 & 2.70 & 0.20 & 0.00 & & & & \\
C11 & 2.70 & 48.40 & 11.60 & 13.90 & $\mathbf{5 8 . 1 0}$ & 53.80 & 0.70 & 2.10 & 0.30 & 56.20 & 0.00 & & & \\
C13 & 39.10 & 39.90 & 20.10 & 14.00 & 58.00 & 23.20 & 0.70 & 2.20 & 0.20 & $\mathbf{9 6 . 6 0}$ & 38.00 & 0.00 & & \\
C14 & 39.10 & 40.00 & 20.00 & 13.90 & 58.10 & 23.20 & 0.70 & 2.20 & 0.20 & $\mathbf{9 6 . 7 0}$ & 37.90 & 49.20 & 0.00 \\
C15 & 39.10 & 39.90 & 20.10 & 14.00 & 58.10 & 23.10 & 0.80 & 2.10 & 0.30 & $\mathbf{9 4 . 1 0}$ & 40.40 & 49.80 & 0.90 & 0.00 \\
Permintaan & $\mathbf{3 9 2 0}$ & 3760 & $\mathbf{2 6 0 0}$ & $\mathbf{2 2 0 0}$ & $\mathbf{3 7 0 0}$ & $\mathbf{2 7 0 0}$ & $\mathbf{2 6 0 0}$ & $\mathbf{1 1 2 0}$ & $\mathbf{3 3 8 4}$ & $\mathbf{5 8 6 0}$ & $\mathbf{6 0 0}$ & $\mathbf{4 3 6 8}$ & $\mathbf{4 5 0 0}$ & $\mathbf{6 0 0}$ \\
\hline
\end{tabular}

\subsection{Mengalokasikan Pelanggan ke Kendaraan atau Rute}

Dengan menggunakan saving matrix langkah penggabungan atau pengelompokan akan dimulai dari nilai penghematan terbesar karena kita berupaya memaksimumkan penghematan. Untuk angka yang di bold atau di cetak tebal pada Tabel 3. adalah angka penghematan dan penggabungan rute yang nantinya akan digunakan pada perhitungan berikutnya. Berdasarkan hasil perhitungan Tabel 3 . maka alokasi pelanggan ke kendaraan atau rute berakhir dengan 3 rute, seperti ditampilkan pada Tabel 4. 
Tabel 4. Pengelompokan Pelanggan

\begin{tabular}{llc}
\hline Rute & \multicolumn{1}{c}{ Pelanggan } & $\begin{array}{c}\text { Jumlah } \\
(\text { pcs })\end{array}$ \\
\hline 1 & C6, C9, C7, C8, C5, & 14,104 \\
& C11 & \\
2 & C10, C14, C13, C15 & 15,328 \\
3 & C3, C4, C1, C2 & 12,408 \\
\hline
\end{tabular}

\subsection{Metode Nearest Neighbour}

Setelah alokasi pelanggan ke kendaraan atau rute dilakukan, langkah berikutnya adalah menentukan urutan kunjungan dengan algoritma Nearest Neighbour. Pada prinsipnya kita selalu menambahkan pelanggan yang jaraknya paling dekat dengan pelanggan yang kita kunjungi terakhir, untuk urutan rute 1 , yaitu: a. Pelanggan yang dikunjungi pertama kali adalah pelanggan yang memiliki jarak terdekat dengan titik awal (0) seperti yang ditunjukan pada tabel berikut ini:

Tabel 5. Langkah Pertama Prosedur Nearest Neighbour

\begin{tabular}{cc}
\hline Rute & Jarak $(\mathrm{km})$ \\
\hline $0-$ C6 & 30.6 \\
$0-$ C 9 & 33.6 \\
$0-$ C 7 & 33.1 \\
$0-$ C 8 & 32.6 \\
$0-$ C5 & 31.00 \\
0-C11 & $\mathbf{3 . 2 0}$ \\
\hline
\end{tabular}

b. Selanjutnya untuk menentukan pelanggan kedua dengan memilih pelanggan yang memiliki jarak terdekat dengan pelanggan pertama, yaitu C11 dari pelanggan yang tersisa.

Tabel 6. Langkah Kedua Prosedur

\begin{tabular}{cc}
\multicolumn{2}{c}{ Nearest Neighbour } \\
\hline Rute & Jarak $(\mathrm{km})$ \\
\hline C11 - C6 & $\mathbf{2 7 . 1}$ \\
C11 - C9 & 31.5 \\
C11 - C7 & 31.0 \\
C11 - C8 & 30.6 \\
C11 - C5 & 29.6 \\
\hline
\end{tabular}

c. Selanjutnya untuk menentukan pelanggan ketiga yang merupakan pelanggan terdekat dengan C6 dari pelanggan yang tersisa.
Tabel 7. Langkah Ketiga Prosedur Nearest Neighbour

\begin{tabular}{cc}
\hline Rute & Jarak $(\mathrm{km})$ \\
\hline C6 - C 9 & 5.00 \\
C6 - C7 & 4.60 \\
C6 - C8 & $\mathbf{4 . 4 0}$ \\
C6-C5 & 51.3 \\
\hline
\end{tabular}

d. Selanjutnya untuk menentukan pelanggan keempat yang merupakan pelanggan terdekat dengan $\mathrm{C} 8$ dari pelanggan yang tersisa.

Tabel 8. Langkah Ketiga Prosedur

\begin{tabular}{cc}
\multicolumn{2}{c}{ Nearest Neighbour } \\
\hline Rute & Jarak $(\mathrm{km})$ \\
\hline C8 - C9 & $\mathbf{1 . 2 0}$ \\
C $8-$ C7 & 1.70 \\
C8 - C5 & 53.3 \\
\hline
\end{tabular}

e. Selanjutnya untuk menentukan pelanggan kelima yang merupakan pelanggan terdekat dengan C9 dari pelanggan yang tersisa.

Tabel 9. Langkah Ketiga Prosedur

\begin{tabular}{cc}
\multicolumn{2}{c}{ Nearest Neighbour } \\
\hline Rute & Jarak $(\mathrm{km})$ \\
\hline C9-C7 & $\mathbf{1 . 8 0}$ \\
C9-C5 & 54.3 \\
\hline
\end{tabular}

Setelah C7 ditetapkan menjadi pelanggan kelima, sehingga yang tersisa, yaitu C5, dan C5 akan menjadi pelanggan terakhir yang akan dikunjungi oleh kendaraan pada saat pengiriman, maka kendaraan tersebut akan kembali ke titik awal (0). Tabel 10. adalah hasil pemilahan costumer yang akan dikunjungi dari kendaraan manapun dengan menggunakan prosedur Nearest Neighbour. Selanjutnya menghitung biaya transportasi tanggal 06 Maret 2017 dapat dilihat pada Tabel 11. Selisih perbandingan jarak tempuh dan biaya transportasi rute awal dengan rute perbaikan dapat dilihat pada Tabel 12 . 
Tabel 10. Urutan Pelanggan dengan Nearest Neighbour

\begin{tabular}{cccc}
\hline Rute & Kendaraan & Pelanggan & Jarak (km) \\
\hline 1 & Truk 1 & 0-C11-C6-C8-C9-C7-C5-0 & 122.5 \\
2 & Truk 2 & 0-C15-C13-C14-C10-0 & 97.9 \\
3 & Truk 3 & 0-C2-C1-C4-C3-0 & 146.5 \\
\hline
\end{tabular}

Tabel 11. Biaya transportasi tanggal 06 Maret 2017

\begin{tabular}{|c|c|c|c|c|c|c|c|c|c|c|}
\hline \multirow[b]{2}{*}{$\begin{array}{l}\text { No. } \\
\text { Rute }\end{array}$} & \multirow[b]{2}{*}{ Kendaraan } & \multirow[b]{2}{*}{ Rute Kunjungan } & \multirow[b]{2}{*}{$\begin{array}{c}\text { Jarak } \\
\text { Tempuh } \\
(\mathrm{km})\end{array}$} & \multirow[b]{2}{*}{$\begin{array}{c}\text { Waktu } \\
\text { Tempuh } \\
\text { (jam) }\end{array}$} & \multirow[b]{2}{*}{$\begin{array}{c}\text { Fixed } \\
\text { Cost (Rp) }\end{array}$} & \multicolumn{4}{|c|}{ Variabel Cost } & \multirow[b]{2}{*}{$\begin{array}{c}\text { Total Biaya } \\
\text { Transportasi / } \\
\text { hari (Rp) }\end{array}$} \\
\hline & & & & & & $\begin{array}{l}(1 / \mathrm{km}) \\
(\mathrm{Rp})\end{array}$ & $\begin{array}{c}\text { Jarak } \\
\text { Tempuh } \\
\text { (Rp) }\end{array}$ & $\begin{array}{l}\text { Retribusi } \\
\text { (Rp) }\end{array}$ & $\begin{array}{l}\text { Bongkor } \\
\text { Customer } \\
\text { (Rp) }\end{array}$ & \\
\hline 1 & Truck 1 & $\begin{array}{l}\text { 0-C11- C6-C8- } \\
\text { C9-C7-C5-0 }\end{array}$ & 122.50 & 5.542 & 672,470 & 1,717 & 210,292 & 38,000 & 60,000 & 980,761 \\
\hline 2 & Truck 2 & $\begin{array}{c}\text { 0-C15-C13- } \\
\text { C14-C10-0 }\end{array}$ & 97.90 & 4.132 & 672,470 & 1,717 & 168,062 & 24,000 & 40,000 & 904,531 \\
\hline 3 & Truck 3 & $\begin{array}{c}0-\mathrm{C} 2-\mathrm{C} 1-\mathrm{C} 4- \\
\mathrm{C} 3-0\end{array}$ & 146.50 & 4.942 & 672,470 & 1,717 & 251,492 & 31,500 & 40,000 & 995,461 \\
\hline$\Sigma$ & & & 366.90 & 14.62 & & & & & & $2,880,754$ \\
\hline
\end{tabular}

Tabel 12. Perbandingan Jarak Tempuh dan Biaya Transportasi Rute Awal dan Perbaikan dengan Metode Saving Matrix Tanggal 06 Maret 2017

\begin{tabular}{|c|c|c|c|c|c|c|}
\hline \multirow{2}{*}{ Rute } & \multicolumn{2}{|c|}{ Jarak Tempuh $(\mathrm{km})$} & \multicolumn{2}{|c|}{ Waktu Tempuh (jam) } & \multicolumn{2}{|c|}{ Biaya Transportasi (Rp) } \\
\hline & Rute Awal & Rute Akhir & Rute Awal & Rute Akhir & Rute Awal & Rute Akhir \\
\hline 1 & 94.4 & 122.5 & 3.573 & 5.542 & 888,523 & 980,761 \\
\hline 2 & 96.2 & 97.9 & 3.603 & 4.132 & 891,613 & 904,531 \\
\hline 3 & 58.5 & 146.5 & 2.475 & 4.942 & 801,895 & 995,461 \\
\hline 4 & 125.5 & & 3.592 & & 931,911 & \\
\hline 5 & 71.7 & & 3.695 & & 849,555 & \\
\hline$\Sigma$ & 446.3 & 366.9 & 16.938 & 14.615 & $4,363,496$ & $2,880,754$ \\
\hline Selisih & 79 & & & & & $1,482,743$ \\
\hline
\end{tabular}

Tabel 13. Total jarak tempuh, waktu tempuh dan biaya transportasi

Total Jarak Tempuh (km) $\quad$ Total Waktu Tempuh (jam) $\quad$ Total Biaya Transportasi (Rp) $6,010 \quad 209.1 \quad 46,630,527$

Tabel 14. Perbandingan Jarak Tempuh dan Biaya Transportasi antara Rute Awal Perusahaan dengan Rute Akhir Metode Saving Matrix dan Metode Nearest Neighbour

\begin{tabular}{lcc}
\multicolumn{1}{c}{ Total } & $\begin{array}{c}\text { Kondisi Perusahaan } \\
\text { Saat Ini }\end{array}$ & $\begin{array}{c}\text { Solusi dengan Metode Saving Matrix dan } \\
\text { Nearest Neighbour }\end{array}$ \\
\hline Jumlah Rute & 88 & 49 \\
\hline Jarak Tempuh $(\mathrm{km})$ & 7700.9 & 6010 \\
\hline Biaya Transportasi (Rp) & $75,124,548$ & $46,630,527$ \\
\hline Penghematan Jarak & & $1,690.9$ \\
\hline Efektivitas Jarak (\%) & & $22 \%$ \\
\hline $\begin{array}{l}\text { Pengehematan Biaya } \\
\text { Transportasi }\end{array}$ & \multirow{2}{*}{ Rp 28,494,021 } \\
\hline $\begin{array}{l}\text { Efisiensi Biaya } \\
\text { Transportasi (\%) }\end{array}$ & \multirow{2}{*}{$38 \%$} \\
\hline
\end{tabular}

Total jarak tempuh $(\mathrm{km})$ dan biaya transportasi untuk rute akhir selama satu bulan dapat dilihat pada Tabel 13. Total biaya transportasi yang dikeluarkan oleh PT. IPM selama satu bulan untuk rute akhir dengan menggunakan metode Saving Matrix dan
Nearest Neighbour, yaitu sebesar Rp. $46,630,527$. Dengan 49 rute dan jarak tempuh 6,010 kilometer.

Sementara itu hasil survei awal ke perusahaan diperoleh 88 rute pengiriman barang selama satu bulan dengan biaya 
transportasi sebesar Rp. 75,124,548.-/bulan. Berdasarkan data tersebut peneliti melakukan perbandingan performansi rute awal perusahaan dengan rute akhir hasil penelitian yang disajikan pada Tabel 14.

\section{KESIMPULAN}

Rute pengiriman produk yang paling tepat untuk meminimumkan biaya transportasi di PT. Inti Polymetal hanya sejumlah 49 rute dari 88 rute. Jarak yang harus ditempuh adalah sejauh 6,010 $\mathrm{km} /$ bulan dengan biaya transportasi sebesar Rp. 46,630,527.-/bulan. Dengan demikian, perusahaan dapat megurangi jarak sebesar
$22 \%$ atau 1,690.9 $\mathrm{km}$ dan dapat menghemat biaya transportasi hingga mencapai $38 \%$ atau sebesar Rp. 28,494,021.-/bulan dengan menggunakan 3 unit rental kendaraan tetap dan truk tambahan (on call) sesuai dengan kebutuhan permintaan pelanggan.

Adapun penelitian lanjutan dapat menambahkan variabel tambahan seperti kapasitas alat angkut. Implikasi manajerial dalam penelitian ini, sebaiknya dalam memenuhi kebutuhan permintaan pelanggan, perusahaan dapat menambahkan alat angkut dan menyesuaikan rute yang telah direduksi sehingga akan didapatkan biaya transportasi yang lebih minimum.

\section{DAFTAR PUSTAKA}

Effendi, A., Ngatilah, Y. dan Iriani (2016) "Penentuan Rute Optimal Distribusi Produk dengan Metode Saving Matrix dan Traveling Salesman Problem di PT. Romindo Primavetcom," Journal of Industrial Engineering and Management, 11(1), hal. 26-34. Tersedia pada: http://eprints.upnjatim.ac.id/7102/.

Hutabarat, J. (2008) "Penentuan Jalur Distribusi pada Rantai Supply dengan Metode Saving Matriks," in Prosiding Seminar Nasional Manajemen Teknologi VIII. Surabaya: Program Studi Magister Manajemen Teknologi Institut Teknologi Sepuluh Nopember, hal. 1-7.

Pujawan, I. N. (2005) Supply Chain Management. 1 ed. Surabaya: Gunawidya.

Rahmawati, R., Nazaruddin dan Sari, R. M. (2014) "Usulan Model dalam Menentukan Rute Distribusi untuk Meminimalkan Biaya Transportasi dengan Metode Saving Matrix di PT. XYZ," e-Jurnal Teknik Industri FT USU, 5(2), hal. 6-10.

Sarjono, H. (2014) "Determination of Best Route to Minimize Transportation Costs Using Nearest Neighbor Procedure," Applied Mathematical Sciences, 8(62), hal. 3063-3074. doi: 10.12988/ams.2014.43225. 